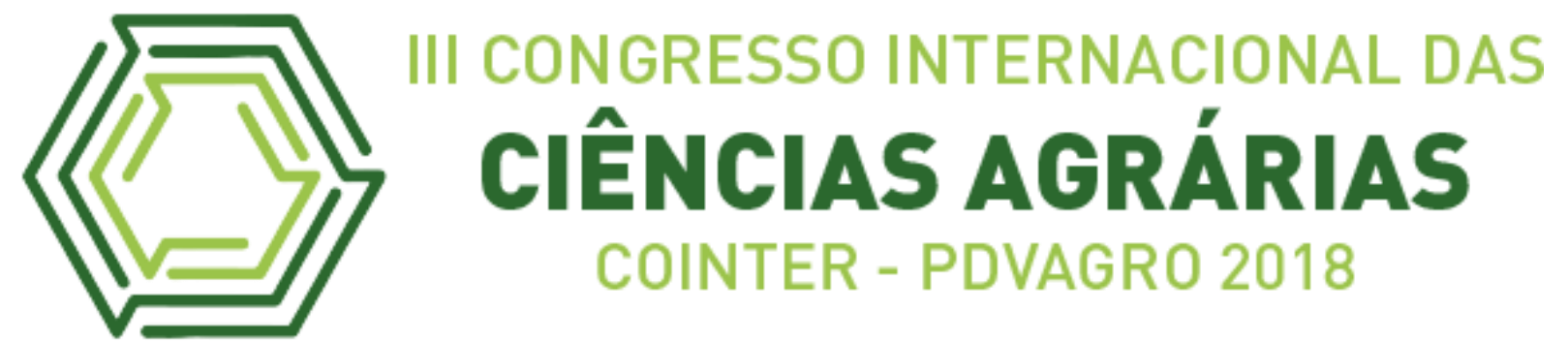

\title{
ELABORAÇÃO E AVALIAÇÃO MICROBIOLÓGICA E ACEITAÇÃO SENSORIAL DE REQUEIJÃO CREMOSO HOMOGENEIZADO COM GOIABADA
}

\section{PREPARATION AND MICROBIOLOGICAL EVALUATION AND SENSORIAL ACCEPTANCE OF CREAM CHEESE HOMOGENIZED WITH GUAVA}

\author{
Apresentação: Pôster \\ Lucivaldo Rodrigues Macário ; Guery Miguel Alves Perreira²; Maria Micheline \\ Teixeira Lopes ${ }^{3}$; Luciana Martins Silva ${ }^{4}$; Otília Mônica Alves Borges ${ }^{5}$ \\ DOI: https://doi.org/10.31692/2526-7701.IIICOINTERPDVAGRO.2018.00461
}

\section{Introdução}

O requeijão cremoso é um tipo de queijo fundido originalmente brasileiro, que está entre os mais produzidos e consumidos no Brasil (VAN DENDER, 2006). De acordo com a Portaria no 359/1997, do Ministério da Agricultura, Pecuária e Abastecimento, requeijão é o produto obtido pela fusão da massa coalhada dessorada e lavada, obtida por coagulação ácida e/ou enzimática do leite, com adição de creme de leite e/ou manteiga e/ou gordura anidra de leite e/ou butter-oil (BRASIL, 1997).

Segundo Gadelha (2016) as frutas têm a função de acrescentar sabor ao ser incorporada em produtos da indústria de alimentos que não possuem muitos atrativos sensoriais, assim como potencializar seus efeitos benéficos à saúde e entre estas frutas utilizadas com essa finalidade está a goiaba. O Brasil é o sétimo maior produtor mundial de goiaba, sendo a região do nordeste brasileiro a maior produtora da fruta (RIBEIRO, 2018).

O objetivo do presente trabalho é externar inovação na elaboração de requeijões, propondo o processamento de formulações que diferem em porcentagem de requeijão e goiabada, avaliar parâmetros de qualidade microbiológica e aceitação sensorial.

\section{Fundamentação Teórica}

A indústria de laticínios, com o crescente aumento do consumo e produção, está em

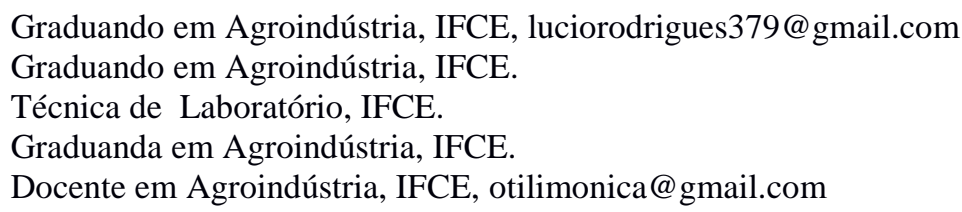


busca de diversificar a gama de produtos ofertados aos consumidores, mostrando tendências e levando a surgir no mercado novos produtos com adição de frutas homogeneizadas em produtos lácteos, como queijos, iogurtes, bebidas lácteas, petit suisse e vários outros produtos (GADELHA, 2016; VAN DENDER, 2006).

Segundo Guedes (2013) uma das vantagens proporcionada pela homogeneização de frutas em lácteos é a agregação de valor ao produto, melhorando os aspectos sensoriais e propondo maiores benefícios à saúde do consumidor, devido à incorporação de nutrientes advindos da fruta. Gadelha (2016) relata que no Brasil o consumo combinado de queijos com doces de goiaba, é uma tradição denominada inclusive de "Romeu e Julieta".

\section{Metodologia}

$\mathrm{O}$ artigo se trata de uma pesquisa quantitativa, do tipo experimental na área da Ciência e Tecnologia de Alimentos. As etapas de processamento foram realizadas no Laboratório de Processamento de Alimentos do Instituto Federal do Ceará (IFCE). Foram elaboradas duas formulações com diferença em porcentagem de goiabada e requeijão cremoso, onde receberam identificação de F1 (50\% de goiabada e 50\% de requeijão cremoso) e F2 (60\% de goiabada e $40 \%$ de requeijão cremoso).

Figura 1: Fluxograma de elaboração das formulações. Fonte: Própria.
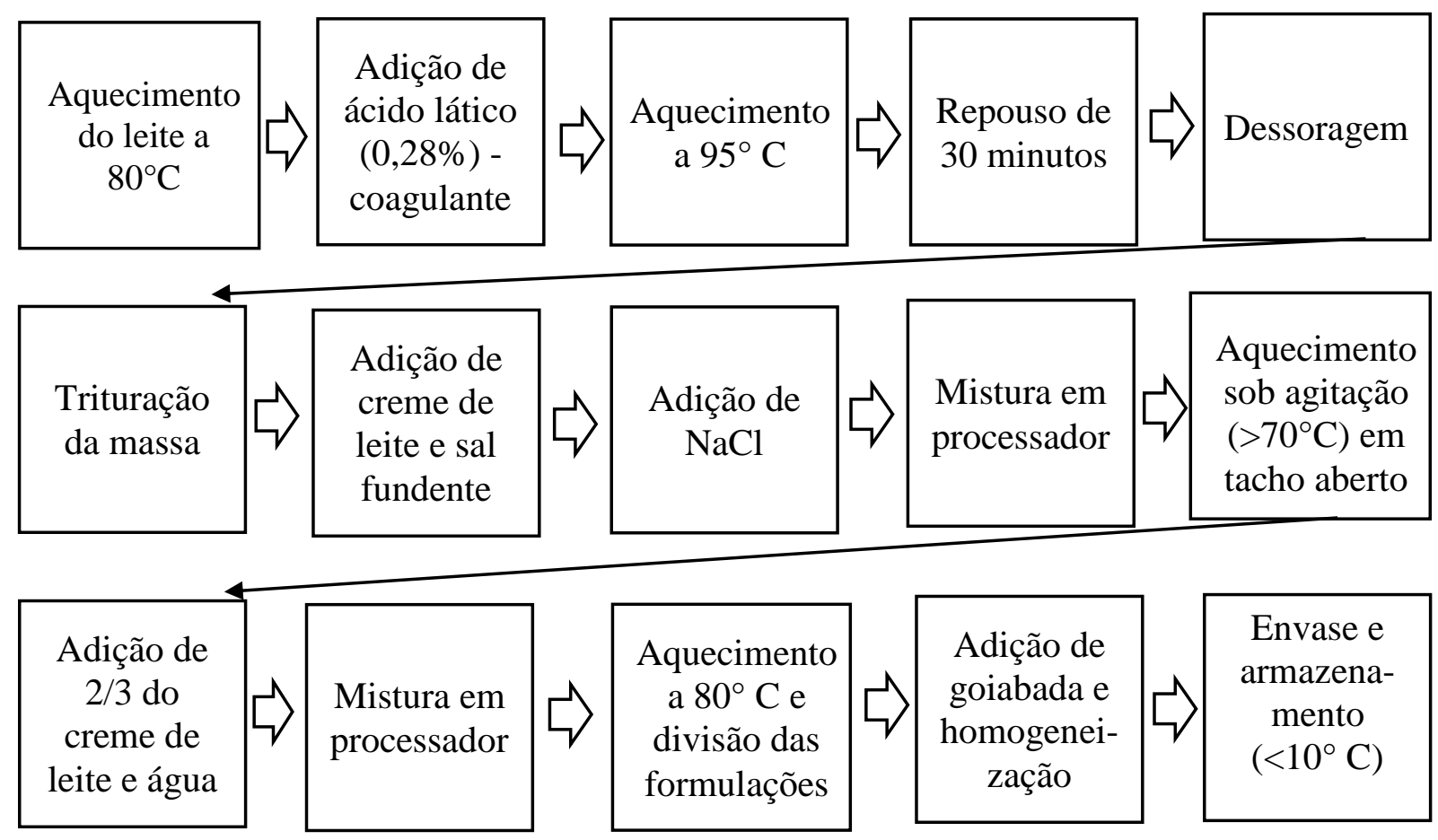
Amostras das formulações foram submetidas a análises microbiológicas de coliformes a $45^{\circ} \mathrm{C}$ e de Staphylococcus coagulase positiva (UFC/g ou $\mathrm{mL}$ ) que foram realizadas no Laboratório de Microbiologia de Alimentos da Universidade Federal do Ceará (UFC), de acordo com APHA, 2001.

A avaliação sensorial das formulações foi realizada por uma equipe de 64 provadores não treinados, com base na acuidade sensorial, utilizando-se testes de escala hedônica estruturada de nove pontos classificatórios e testes de intenção de compra estruturado em cinco pontos também classificatórios de acordo com metodologia descrita por Meilgaard, Civille e Carr (1999).

Os testes foram realizados em cabines individuais iluminadas com lâmpadas fluorescentes, servidos monadicamente, sob condições controladas. Cada indivíduo recebeu uma amostra de 20 gramas, em copos codificados com números aleatórios de três dígitos, duas torradas e um copo contendo água, para que o provador limpasse o palato ao provar a amostra seguinte.

\section{Resultados e Discussões}

As contagens de coliformes a $45^{\circ} \mathrm{C}$ se apresentaram $<3 \mathrm{NMP} / \mathrm{g}$ e de Staphylococcus coagulase positiva (UFC/g ou $\mathrm{mL}$ ) com contagem $<10$.

As contagens corroboraram com o que preconiza a Resolução RDC $n^{\circ} 12$, de 02 de janeiro de 2001 (BRASIL, 2001), que define os padrões microbiológicos para cada alimento.

Em relação ao produto lácteo fundido "requeijão", a referida resolução determina tolerância de coliformes a $45^{\circ} \mathrm{C}$ para a amostra indicativa $<10 \mathrm{NMP} / \mathrm{g}$ e para Staphylococcus coagulase positiva (UFC/g ou $\mathrm{mL}$ ) $<10^{3} \mathrm{NMP} / \mathrm{g}$. Com os resultados obtidos pode-se afirmar que as formulações foram processadas e acondicionadas de forma segura. Gadelha (2016) ao elaborar e avaliar requeijão cremoso caprino com teor reduzido de lactose para consumo combinado com geleia de goiaba também obtive contagem microbiológica em conformidade com a legislação para coliformes a $45^{\circ} \mathrm{C}$ e Staphylococcus coagulase positiva (UFC/g ou mL).

Os provadores que realizaram os testes sensoriais tinham faixa etária entre 17-25 anos (78,13\%), seguido por 26-34 anos (14,06\%) e 35-43 anos (7,81\%). Quanto ao perfil de gênero $56,25 \%$ dos provadores foram mulheres e $43,75 \%$ homens.

De acordo com os gráficos 1 e 2 observam-se os valores das frequências acumuladas correspondentes as notas atribuídas para aparência, aroma, sabor, textura e impressão global para a formulação F1 e F2 de requeijão homogeneizado com goiabada. 
Gráfico 1: Histograma de frequência de notas atribuídas a formulação F1. Fonte: Própria.

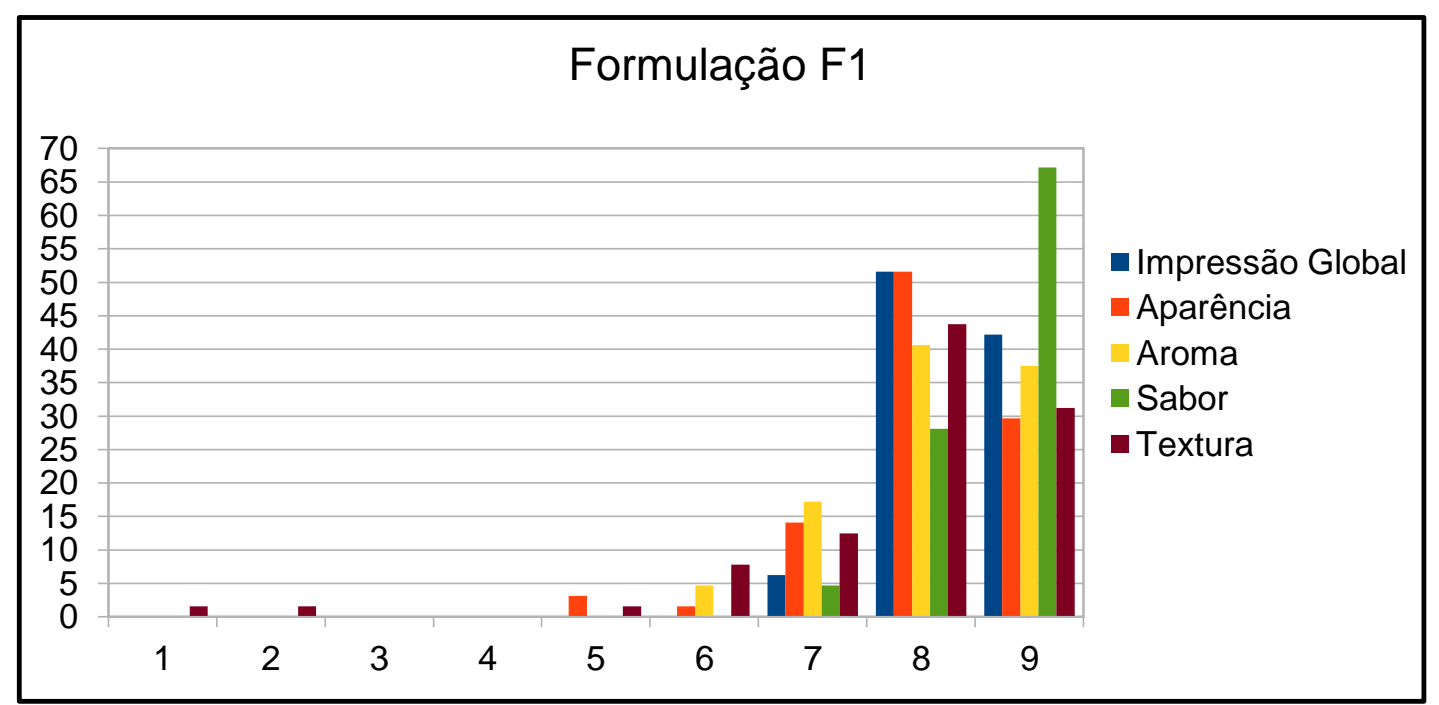

Gráfico 2: Histograma de frequência de notas atribuídas a formulação F2. Fonte: própria

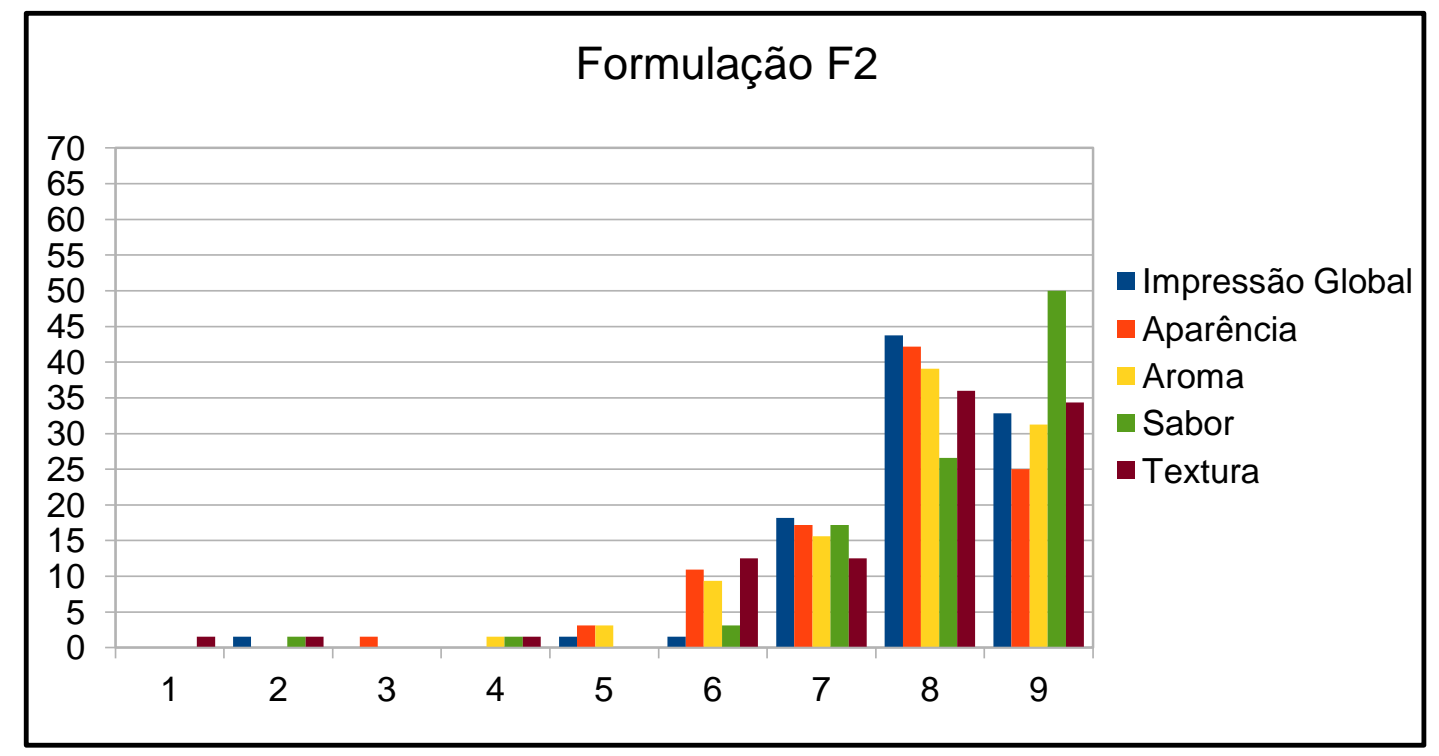

A impressão global da formulação F1 acumulou frequência de 42,19\% correspondente a nota 9 na classificação "gostei extremamente" e 51,56\% na classificação hedônica 8 "gostei muito". A formulação F2 acumulou frequência de 32,81\% em impressão global classificação 9 “gostei extremamente" e 43,75\% na nota 8 , classificação "gostei muito".

TORRES (2015) encontrou para impressão global resultado em classificação inferior ao deste estudo ao realizar estudo das características sensoriais de requeijões comercias, a autora obteve classificação 7 "gostei moderadamente". Os resultados desta pesquisa em frequência acumulada se encontraram dentro da faixa de aceitação entre as categorias 6 
"gostei ligeiramente" à categoria 9 "gostei extremamente" para os atributos aparência, aroma, aroma, sabor e textura de ambas formulações. Resultados semelhantes foram obtidos Gadelha (2016) ao avaliar requeijão cremoso caprino com teor reduzido de lactose para consumo combinado com geleia de goiaba, a autora obteve classificações de frequência acumulada, da mesma forma que neste estudo entre as categorias 6 "gostei ligeiramente" à categoria 9 "gostei muitíssimo".

Os resultados de intenção de compra para as formulações se encontram no Gráfico 3.

Gráfico 3: Histograma de frequência de Intenção de compra. Fonte: Própria.

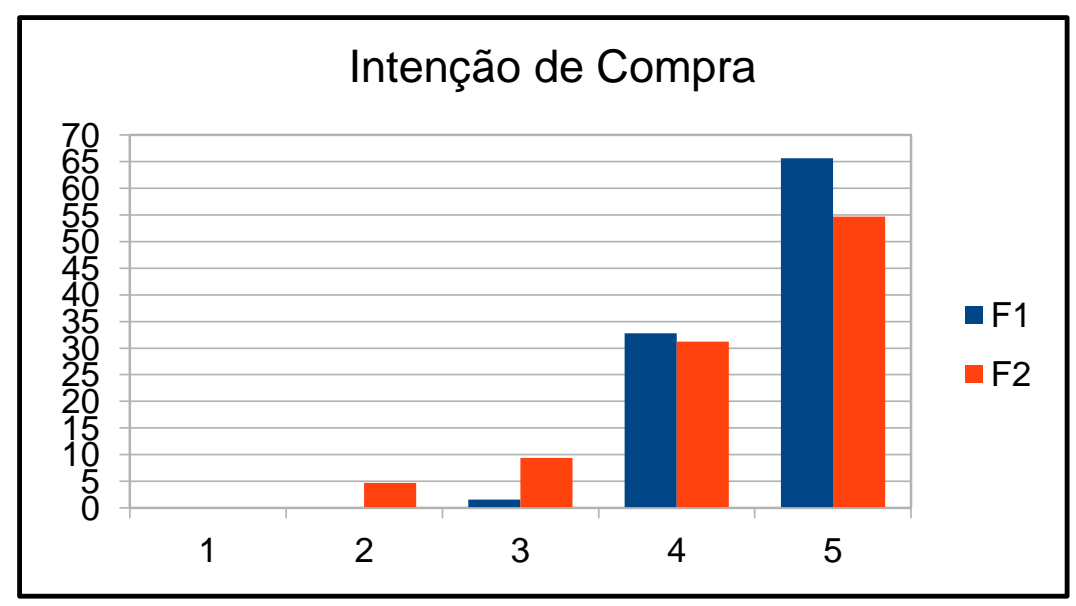

A formulação F1 acumulou frequência de $65,62 \%$ na classificação 5 "certamente compraria" e 32,81\% na classificação 4 "provavelmente compraria", ficando com melhor intencionamento de compra, em relação a F2 que recebeu para a classificação 5 "certamente compraria" 54,69\% de frequência acumulada e 31,25\% na classificação 4 "provavelmente compraria”. Torres (2015) obteve resultado semelhante de intenção de compra, contudo a autora para algumas amostras obteve classificações inferiores ao deste estudo ao avaliar por teste sensorial requeijões comercias.

\section{Conclusões}

Conclui-se que a inovação do lácteo requeijão cremoso homogeneizado com goiabada foi exitosa, visto que a junção dos insumos resultou em um produto com características próprias.

Os resultados microbiológicos se encontraram em conformidade e a aceitação sensorial foi satisfatória para as duas formulações, contudo, a formulação F1 foi a mais bem- 
aceita, pois ficou com melhor classificação hedônica sensorial e de intenção de compra.

\section{Referências}

AMERICAN PUBLIC HEALT ASSOCIATION. Compendium of methods for the microbiological examination of foods. Washington, 2001.

BRASIL. Agência Nacional de Vigilância Sanitária - Anvisa. Resolução $\mathrm{n}^{\circ}$ 12, de 02 de Janeiro de 2001. Aprovar o Regulamento Técnico Sobre Padrões Microbiológicos Para Alimentos. Diário Oficial da República Federativa do Brasil, Brasília-DF, 2001.

BRASIL. Ministério da Agricultura, Pecuária e Abastecimento. Secretaria de Defesa Agropecuária. Regulamentos Técnicos de Identidade e Qualidade de Leite e Produtos Lácteos. Portaria $\mathrm{n}^{\circ} 359$ de 04 de setembro de 1997. Regulamento técnico para fixação de identidade e qualidade do requeijão cremoso ou requesón. Diário Oficial da União, Brasília-DF, 1997.

GADELHA, G. B. O. Elaboração e avaliação de requeijão cremoso caprino com teor reduzido de lactose para consumo combinado com geleia de goiaba. 2016. $80 \mathrm{f}$. Dissertação (Mestrado em Ciência e Tecnologia de Alimentos) - Universidade Federal do Ceará, Centro de Ciências Agrárias, Programa de Pós-Graduação em Ciência e Tecnologia de Alimentos, Fortaleza, 2016.

GUEDES, A. F. L. M. et al. Aproveitamento de soro lácteo na formulação de bebidas com frutas e hortaliças. Periódico Arquivo Brasileiro de Medicina Veterinária e Zootecnia, Belo Horizonte, v. 65, n. 4, p. 1231-1238, 2013.

MEILGAARD, M.; CIVILLE, G.V.; CARR, B.T. Sensory Evaluation Techniques. New York: Boca Raton, 3 ed. 1999. 387p.

RIBEIRO, L.R. O cultivo e o mercado de goiabas no Brasil. Revista Campo e Negócios, Hortifrúti. UNESP/ Botucatu 22/06/2018.

TORRES, F. R. Estudo das características sensoriais, físicas e químicas em requeijão cremoso tradicional e adicionado de amidoe gordura vegetal, obtidos no mercado varejista. 2015. 75 f. Dissertação (Mestrado em Higiene Veterinária e Processamento Tecnológico de Produtos de Origem Animal) - Programa de pós-graduação em medicina veterinária, Universidade Federal Fluminense, Niterói, 2015.

VAN DENDER, A. G. F. Requeijão cremoso e outros queijos fundidos: tecnologia de fabricação, controle do processo e aspectos de mercado. São Paulo: Fonte de Comunicações, 2006. 391 p. 